Research Article

\title{
Breakage Mechanism of Layered Sandstone Penetrated by TBM Disc Cutter
}

\author{
Yingji Bao $\mathbb{D}^{1},,^{1,2}$ Jianlong Cheng $\mathbb{D}^{1,3}$ and Binsong Jiang ${ }^{1}$ \\ ${ }^{1}$ State Key Laboratory for Geomechanics and Deep Underground Engineering, China University of Mining and Technology, \\ Xuzhou 221116, China \\ ${ }^{2}$ School of Transportation Engineering, Jiangsu Vocational Institute of Architectural Technology, Xuzhou 221116, China \\ ${ }^{3}$ State Key Laboratory of Geohazard Prevention and Geoenvironment Protection, Chengdu University of Technology, \\ Chengdu 610059, China
}

Correspondence should be addressed to Jianlong Cheng; chengj12018@foxmail.com

Received 31 December 2020; Revised 25 January 2021; Accepted 3 February 2021; Published 3 March 2021

Academic Editor: Zang Chuanwei

Copyright (c) 2021 Yingji Bao et al. This is an open access article distributed under the Creative Commons Attribution License, which permits unrestricted use, distribution, and reproduction in any medium, provided the original work is properly cited.

In this paper, the breakage mechanism of layered sandstone subjected to the TBM disc cutter was investigated. A series of typical layered sandstone specimens were prepared for true triaxial compression tests in the laboratory to simulate the disc cutter action at the tunnel face, and an acoustic emission (AE) system was used to monitor the breaking process during the penetration tests. Furthermore, a DV recorder was employed to capture the surface deformation. Then, the failure specimens were scanned by high resolution X-ray micro-CT. The results show that the failure mode of layered sandstone in terms of cracking transforms into local crushing with increasing confining stress. The propagation pattern of the cracks varies with the bedding inclination, which is distinctly different from intact rock. The results also indicate that the peak force presents linear variation with the confining stress and an increasing trend with the bedding inclination at the first penetration, and the failure mode of the second penetration is mainly related to the broken status from the first penetration.

\section{Introduction}

Layered rocks have distinct anisotropy, which has an important impact on the advance rate and cutting efficiency of the TBM. Therefore, studying the breakage mechanism of layered sandstone penetrated by the TBM disc cutter is significant [1-5]. Yin et al. [6] conducted full-scale linear cutting tests on granite samples with different joint spacings; cracks initiated from the crushed zone under the TBM cutter, and cracks propagated to the joint plane two fragmentation modes found at small joint spacings. With increasing joint spacing, the fragmentation modes transformed to the normal rock fragmentation stage and jointcontrolled rock fragmentation stage. It was also found that joints can restrain crack propagation across the joint plane and facilitate chip formation on the cutting surface. Yang et al. $[7,8]$ conducted a miniature cutter rolling indentation abrasion test (RIAT) on prefabricated joint rock samples.
The influences of joint orientation and spacing on cutting forces and penetration were analysed, and the differences in crack propagation patterns and fractured work were compared. Afrasiabi et al. [9] studied TBM performance at real-scale by simulating the cutter head in real dimensions by using $\mathrm{PFC}^{3 \mathrm{D}}$. The influences of the orientation and spacing of joints on TBM performance in hard rock were investigated, and the results indicated that a $60^{\circ}$ angle of the joints with the TBM axis of advance had the greatest effect on TBM performance, and a zero angle had the least effect. Zhao et al. [10] conducted rolling boring tests and ANSYS simulations to study the influence of joint orientations, spacings, RAI and interlayers on cutting efficiency and cutter wear, and quantifiable fitting formulas for $S_{E}$ and wear were proposed.

During rock cutting by the disc cutter, the normal force is known to be a dominant effect. Therefore, many researchers have conducted quasistatic penetration tests and 


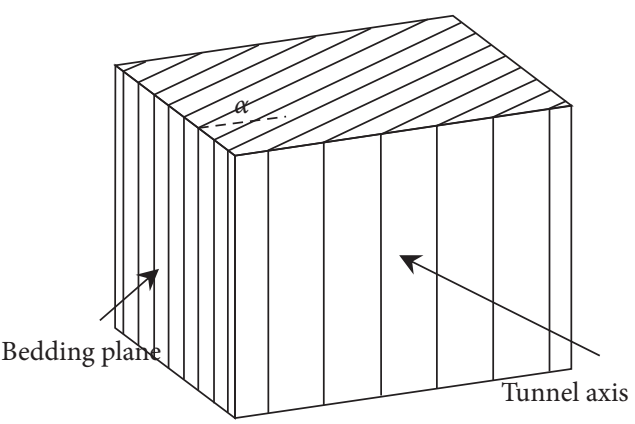

(a)

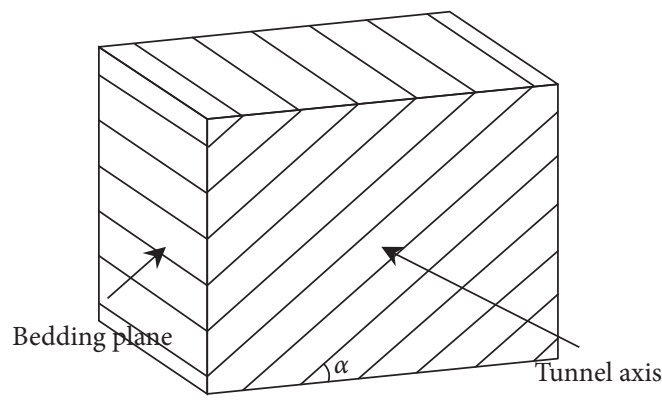

(b)

FIGURE 1: Sketch of the bedding plane and tunnel axis (indentation direction).

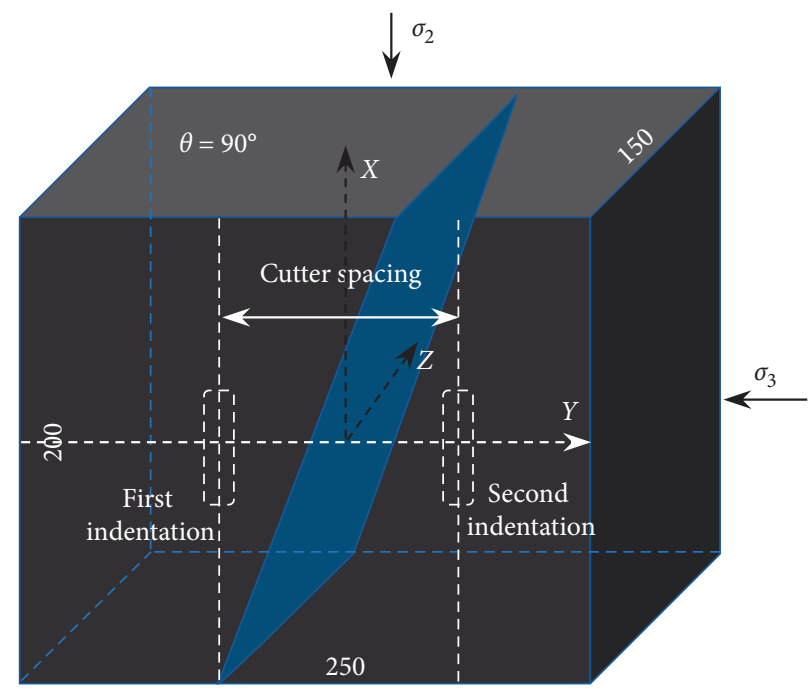

Figure 2: Two indentations of layered specimen used by TBM disc cutter.

simulations to study the mechanical responses and failure characteristics of disc cutters [11-16]. Gong et al. [17, 18] and Bejari and Khademi Hamidi [19] studied the effects of joint orientation and joint spacing on crack propagation and chip formation by using the UDEC. The results showed that cutting efficiency decreases with increasing joint spacing in a given joint orientation. Additionally, the cutting efficiency initially increases from $0^{\circ}$ to $60^{\circ}$ and then decreases up to $90^{\circ}$ with definite joint spacing. Zhai et al. [20] studied the crack initiation and propagation pattern of consecutive joints in different joint orientations and intermittent joints of different lengths by using general particle dynamic (GPD). Liu et al. [21] applied 3DEC to simulate the rock fragmentation process for mixed ground characteristics by double TBM cutters, and the effects of joint spacing, joint orientation, and confining stress on crack propagation and specific energy were investigated. Zhang et al. [22] conducted rock cutting tests with a wedge cutter and PFC2D simulations to study the crack propagation and the force chain evolution of mixed ground. Eftekhari et al. [23] constructed twodimensional discrete fracture network (2D-DFN) models with different fracture length distributions by using the UDEC, and the influence of the fracture pattern on the penetration rate of a TBM in fractured rock masses was investigated.

However, these existing tests and simulations were mainly focused on vertical bedding, and the angle between the tunnel axis and bedding strike is ranging from $0^{\circ}$ to $90^{\circ}$, whereas the tunnel axis parallel to the bedding strike with different inclinations has less been investigated (Figure 1). Therefore, in this paper, penetration tests were conducted on rocks with these bedding features by the disc cutter under different confining stresses and bedding inclinations. Furthermore, a DV recorder and an acoustic emission (AE) system were used to monitor the surface and internal breaking process during the tests. Then, typical specimens were scanned by high-resolution X-ray micro-CT, and the distribution characteristics of internal cracks were revealed.

\section{Experimental Procedure}

2.1. Experimental Design. The layered sandstone specimen penetrated by the TBM disc cutter is shown in Figure 2. The specimen was shaped into a rectangular block $(250 \mathrm{~mm}$ in length, $200 \mathrm{~mm}$ in width, and $150 \mathrm{~mm}$ in thickness) with different bedding inclinations $\left(0^{\circ}, 30^{\circ}, 45^{\circ}, 60\right.$, and $\left.90^{\circ}\right)$. The 

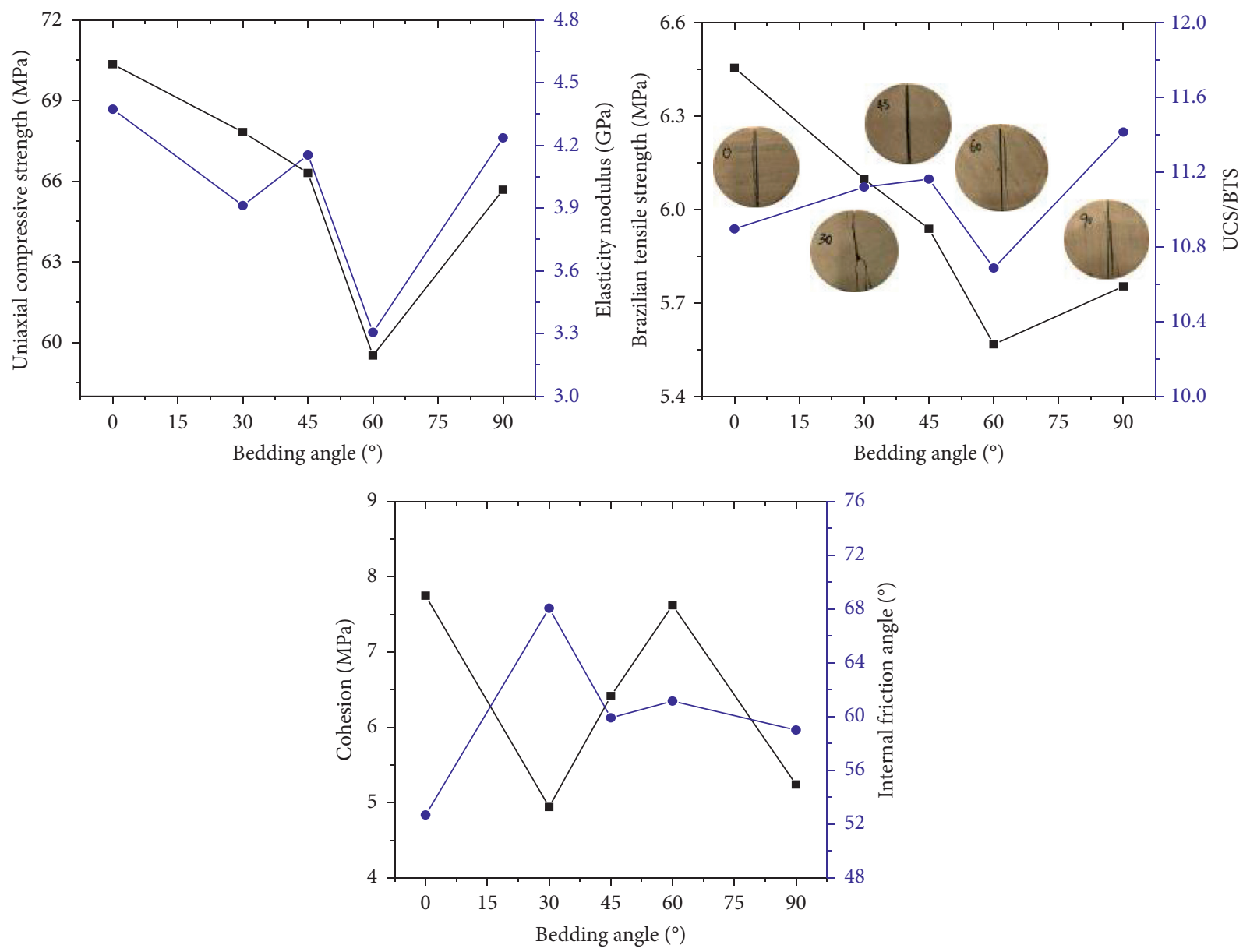

FIgURE 3: The variations in the main mechanical parameters with the inclination angle.

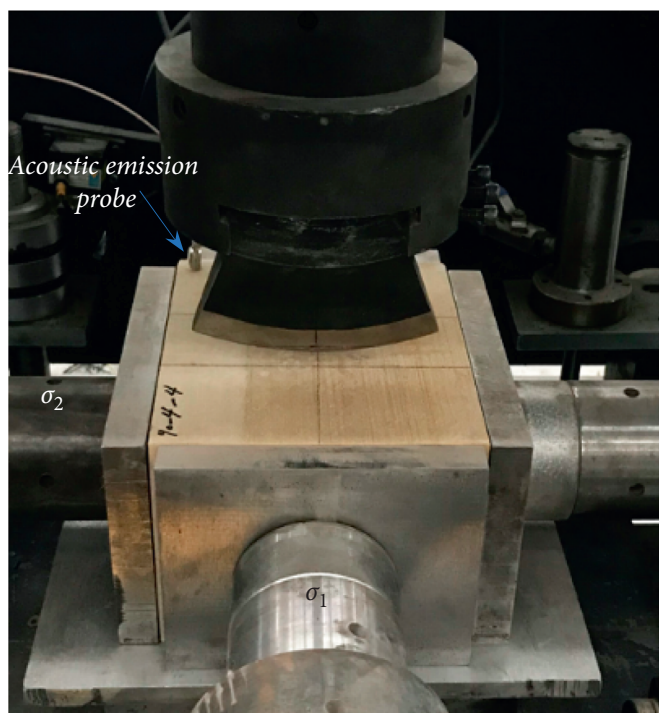

(a)

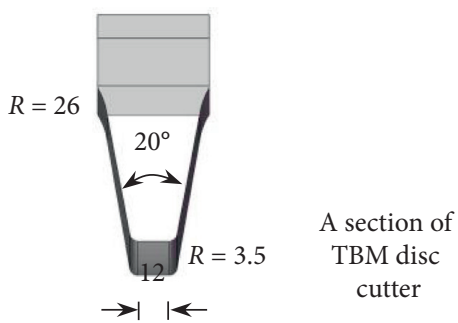

Outline of 17-inch TBM disc cutter

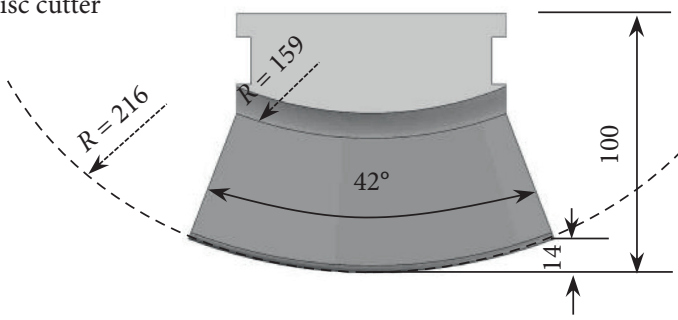

(b)

FIgURE 4: Testing system and geometry of penetration tool. 

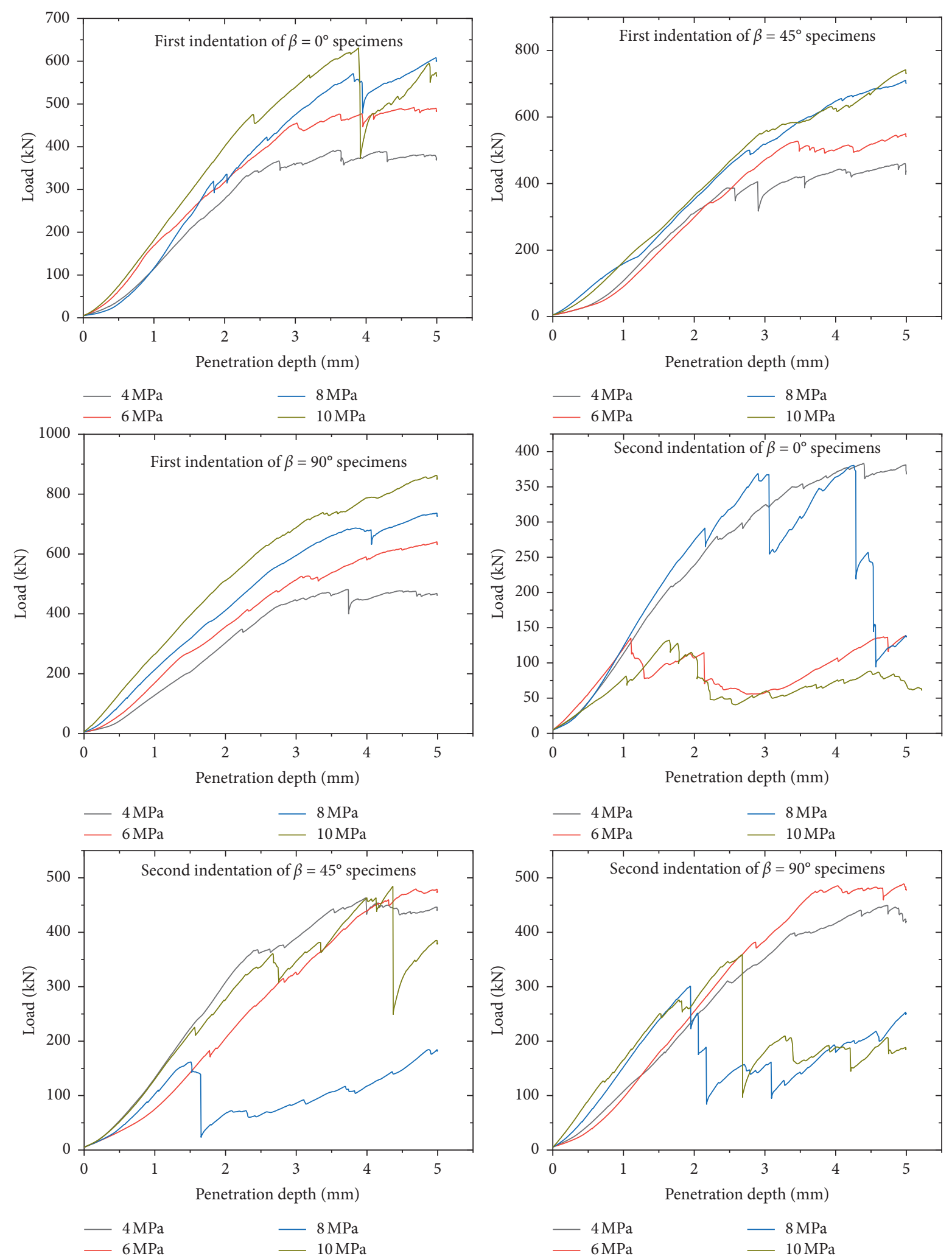

FIgURE 5: The first and second typical load-penetration depth curves.

bedding plane is vertical to the surface of the specimen to be penetrated, as shown in Figure 2. During the loading process, two perpendicular loading directions on the side of the specimen were subjected to stresses $\sigma_{2}(4 \mathrm{MPa})$ and $\sigma_{3}(4 \mathrm{MPa}$, $6 \mathrm{MPa}, 8 \mathrm{MPa}$, and $10 \mathrm{MPa}$ ) to create a biaxial confining stress condition. Then, sequential penetration was conducted on the 
TABLE 1: The peak force, removed volume, and specific energy for all the tested layered samples.

\begin{tabular}{|c|c|c|c|c|c|c|c|c|c|}
\hline Number & $\begin{array}{c}\text { Inclination } \\
\alpha\left({ }^{\circ}\right)\end{array}$ & $\begin{array}{c}\sigma 2 \\
(\mathrm{MPa})\end{array}$ & $\begin{array}{c}\sigma 3 \\
(\mathrm{MPa})\end{array}$ & $\begin{array}{l}\text { Peak force, } \\
1^{\text {st }}(\mathrm{kN})\end{array}$ & $\begin{array}{l}\text { Peak force, } \\
2^{\text {nd }}(\mathrm{kN})\end{array}$ & $\begin{array}{c}\text { Energy in } \\
1^{\text {st }}(\mathrm{J})\end{array}$ & $\begin{array}{l}\text { Energy in } \\
2^{\text {nd }}(J)\end{array}$ & $\begin{array}{c}\text { Removed } \\
\text { volume }\left(\mathrm{cm}^{3}\right)\end{array}$ & $\begin{array}{c}\text { Specific energy } \\
\left(\mathrm{J} / \mathrm{cm}^{3}\right)\end{array}$ \\
\hline $0-4-4$ & 0 & 4 & 4 & 392.05 & 383.21 & 1336.61 & 1239.41 & 15.52 & 0.38 \\
\hline $0-6-4$ & 0 & 6 & 4 & 491.6 & 139.00 & 1648.50 & 433.81 & 270.81 & 0.02 \\
\hline $0-8-4$ & 0 & 8 & 4 & 608.16 & 380.52 & 1769.08 & 1112.02 & 164.87 & 0.04 \\
\hline $0-10-4$ & 0 & 10 & 4 & 630.79 & 132.33 & 1945.03 & 352.81 & 640.93 & 0.01 \\
\hline $30-4-4$ & 30 & 4 & 4 & 464.68 & 378.13 & 1374.40 & 1158.58 & 14.52 & 0.40 \\
\hline $30-6-4$ & 30 & 6 & 4 & 573.77 & 543.73 & 1685.98 & 1630.39 & 17.58 & 0.43 \\
\hline $30-8-4$ & 30 & 8 & 4 & 645.98 & 304.19 & 1912.62 & 826.39 & 177.31 & 0.04 \\
\hline $30-10-4$ & 30 & 10 & 4 & 809.43 & 411.32 & 2334.61 & 1325.17 & 117.12 & 0.07 \\
\hline $45-4-4$ & 45 & 4 & 4 & 460.19 & 463 & 1473.67 & 1511.53 & 32.08 & 0.21 \\
\hline $45-6-4$ & 45 & 6 & 4 & 549.83 & 479.49 & 1639.90 & 1296.42 & 23.59 & 0.28 \\
\hline $45-8-4$ & 45 & 8 & 4 & 710.53 & 184.44 & 2036.73 & 477.04 & 204.51 & 0.03 \\
\hline $45-10-4$ & 45 & 10 & 4 & 741.99 & 484.90 & 2064.67 & 1374.92 & 81.62 & 0.10 \\
\hline $60-4-4$ & 60 & 4 & 4 & 502.79 & 168.37 & 1669.07 & 449.65 & 311.17 & 0.02 \\
\hline $60-6-4$ & 60 & 6 & 4 & 611.52 & 631.47 & 1629 & 2007.56 & 11.01 & 0.75 \\
\hline $60-8-4$ & 60 & 8 & 4 & 770.79 & 706.53 & 2429.14 & 2174.04 & 88.03 & 0.12 \\
\hline $60-10-4$ & 60 & 10 & 4 & 826.28 & 235.48 & 2694.19 & 772.88 & 243.91 & 0.03 \\
\hline $90-4-4$ & 90 & 4 & 4 & 481.30 & 449.29 & 1571.29 & 1351.38 & 72.84 & 0.09 \\
\hline $90-6-4$ & 90 & 6 & 4 & 640.70 & 488.92 & 1935.53 & 1469.48 & 43.66 & 0.18 \\
\hline $90-8-4$ & 90 & 8 & 4 & 736.72 & 300.97 & 2281.99 & 809.78 & 143.61 & 0.05 \\
\hline $90-10-4$ & 90 & 10 & 4 & 862.54 & 387.57 & 2692.65 & 1097.49 & 171.88 & 0.05 \\
\hline
\end{tabular}

Note. The $a, b$, and $c$ symbols of $a-b-c$ for each specimen number indicate the inclination, the maximum principal stress, and the minimum principal stress, respectively.

specimen in the $\sigma_{1}$ direction. The first and second indentation locations were marked on the surface, the cutting spacing was $70 \mathrm{~mm}$, and the indentation depth was $5 \mathrm{~mm}[24,25]$.

2.2. Rock Sample. The sandstone specimens prepared for this research were from Zigong, Sichuan Province, China. The sandstone appearance was light yellow and showed distinct bedding lines, and its approximate bulk density was $2268 \mathrm{~kg} /$ $\mathrm{m}^{3}$. Because the bedding inclinations exert an obvious influence on the strength and elasticity modulus, a series of cylindrical specimens with sizes of $\Phi 50 \times 100 \mathrm{~mm}$ and $\Phi 50 \times 25 \mathrm{~mm}$ were prepared to determine the conventional physical and mechanical parameters of the rock material, including density, Young's modulus, Poisson's ratio, Brazilian tensile strength (BTS), cohesion, friction angle, and uniaxial compressive strength (UCS). The variations in these parameters along with the bedding inclination are plotted in Figure 3.

2.3. Testing Method. The layered sandstone specimens in this research were tested on the true triaxial compression system shown in Figure 4(a). The test system consisted of a three-dimensional servo control system in the $\sigma_{1}, \sigma_{2}$, and $\sigma_{3}$ directions, and the corresponding maximum loading capacities were $1600 \mathrm{kN}, 500 \mathrm{kN}$, and $300 \mathrm{kN}$. There were two loading modes in which force and displacement could be selected, the sensor of force mode is spoke type with a precision of $0.01 \mathrm{kN}$, and the sensor of displacement mode is rope type with an accuracy of $0.002 \mathrm{~mm}$. In this research, the displacement mode was employed, and the loading rate was $0.3 \mathrm{~mm} / \mathrm{min}$, which ensured that the test was conducted under a quasistatic loading condition. The penetration tool was a 17 -inch TBM disc cutter, and a holder was designed to mount the disc cutter and allow it free movement in a groove to adjust its indentation location. The shape and size of the disc cutter are shown in Figure 4(b).

A testing programme was designed to study the breakage mechanism of the layered sandstone penetrated by the TBM disc cutter under different confining stresses and bedding inclinations. The specimen was placed on a true triaxial compression system, and there were four thick steel plates surrounding it. Then, the disc cutter was set to a specified location (shown in Figure 3) for the first penetration. The test was initiated by exerting a biaxial load by force control at a constant loading rate of $1 \mathrm{kN} / \mathrm{s}$. The load remained constant once the force reached the preset value. Next, a vertical load was applied by force control at a loading rate of $0.5 \mathrm{kN} / \mathrm{s}$ until the disc cutter contacted the specimen. Then, the loading mode changed to displacement control at a loading rate of $0.3 \mathrm{~mm} / \mathrm{min}$ and was terminated once the penetration depth reached $5 \mathrm{~mm}$. Subsequently, the disc cutter was lifted up and horizontally moved a distance of $70 \mathrm{~mm}$ for the second penetration. The testing procedure was the same as the first penetration. In addition, as shown in Figure 4(a), an $\mathrm{AE}$ sensor was used to record the $\mathrm{AE}$ event during the failure process.

\section{Analysis of the Experimental Results}

3.1. Typical Indention Force-Penetration Depth Curves. Figure 5 shows the load-penetration depth curves of the layered sandstone under different confining stresses and bedding inclinations for the first and second penetrations. From Figure 5, according to the first penetration curves, the 

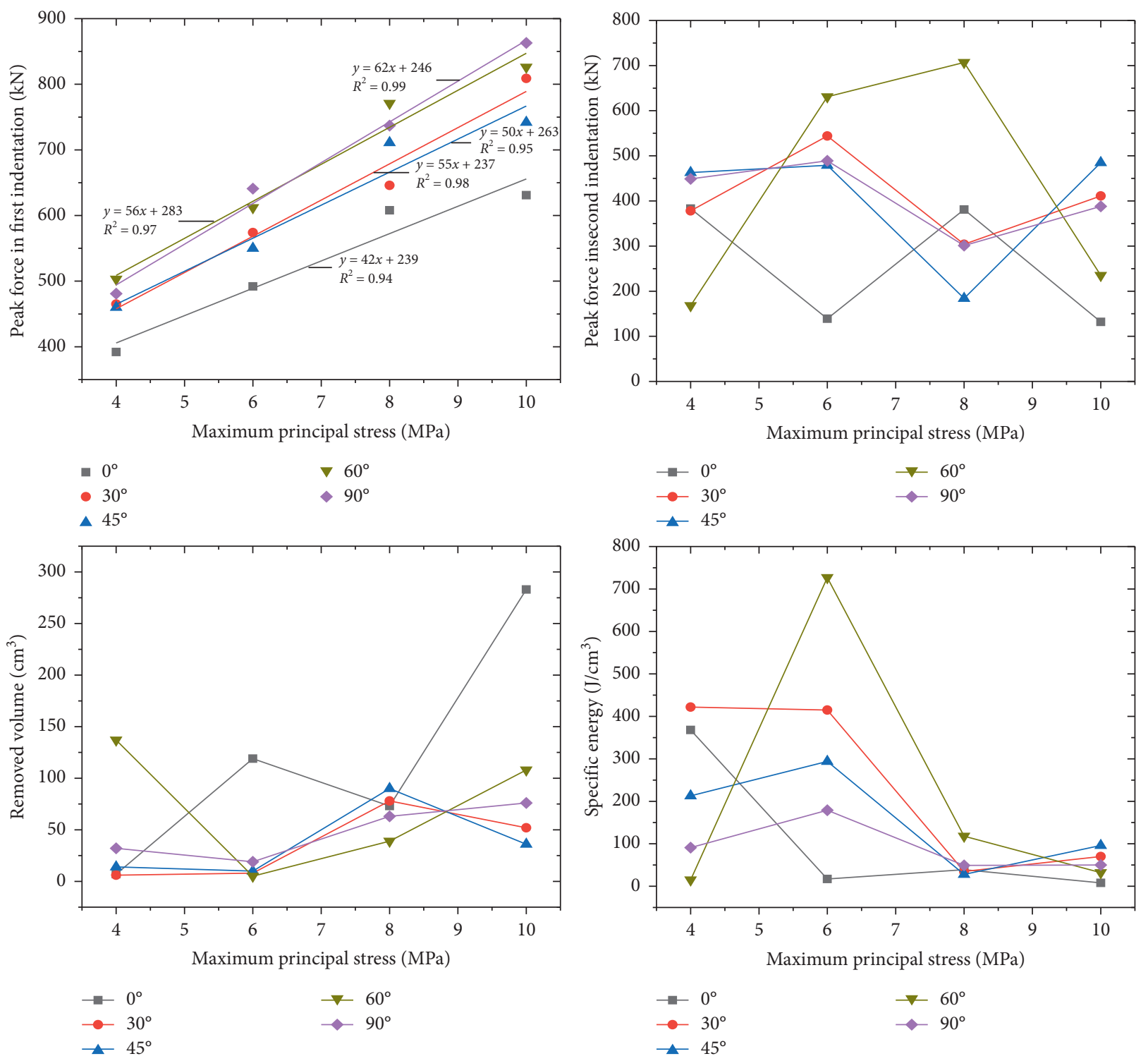

Figure 6: Comparison of the peak forces between the first and second penetrations.

microcrack evolution can be roughly divided into three stages: stage I is the initial compaction stage; stage II is the constant rigid penetration stage; and stage III is the sustained failure stage. At low confining stress, the loadpenetration depth curve of stage I reveals a distinct upward concave trend because the preexisting microcracks in the specimens are closed by the loading force. With increasing confining stress, more preexisting microcracks are closed before penetration; thus, the concave portion of the curve of stage I at high confining stress is less distinct. Furthermore, under the same confining stress, the concave extent of the curve at a bedding inclination of $\alpha=90^{\circ}$ is smaller than that at $\alpha=0^{\circ}$, which indicates that penetration is easier when the disc cutter in the same direction with the bedding plane. In stage II, the curve is a nearly straight line. With increasing penetration depth, irreversible damage begins to occur, and the curve bends down to the failure stage. In stage III, the microcracks increase rapidly and accumulate to a high level, and the loading forces reach several local peaks and drop to a small extent. Then, the loading force increases smoothly again, and the specimen is subjected to loading until the penetration depth reaches $5 \mathrm{~mm}$. Subsequently, the curve bends downward and tends towards the horizontal. For the second penetration in Figure 5, the peak loading force is obviously lower than that for the first penetration. Furthermore, the shapes of the curves vary under different confining stresses and bedding inclinations, which indicates that the failure of the second penetration is related to the broken mode and range of the first penetration. The peak force, total energy, removed volume, and specific energy values of the first and second penetrations are listed in Table 1. The specific energy is the energy requirement for the cutting unit volume of the rock fragments, which is the ratio of the total energy to the total removed volume by the two penetrations defined here. The specific energy is an important parameter for assessing the performance of the TBM. 

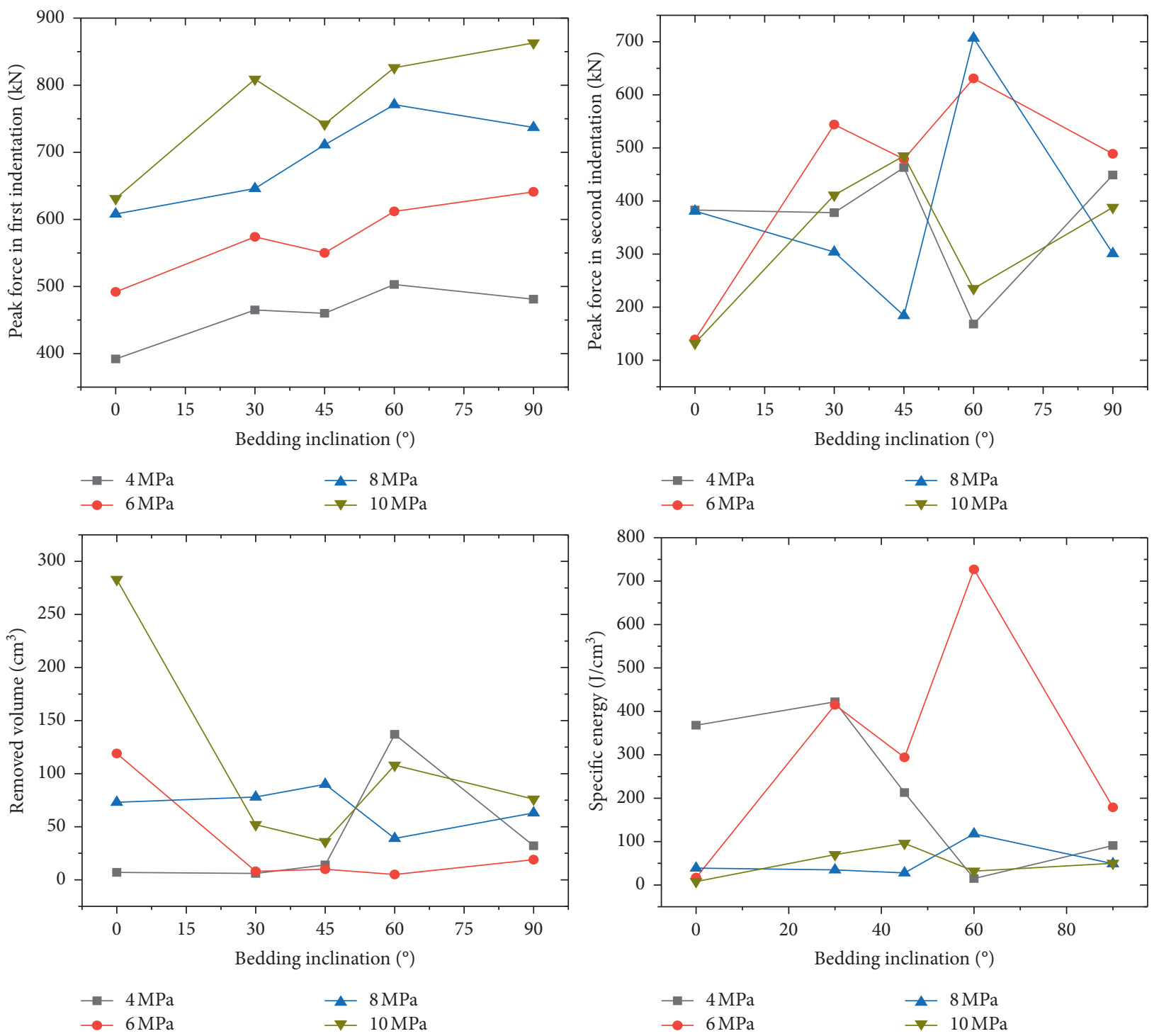

Figure 7: Effects of bedding inclination and confining stress on specific energy.

3.2. Effect of Confining Stress on Penetration Behaviour. Figure 6 shows the variations in the peak force, removed volume, and specific energy with the maximum principal stress. We can see that the peak force in the first penetration increases gradually along with the confining stress, approximating a linear variation and resulting in a high degree of fitting. However, in the second penetration, the peak forces fluctuate acutely with the confining stress and occur with no particular pattern. The maximum variation appears at $\alpha=60^{\circ}$, which indicates that the failure mode of the second penetration is influenced by the first penetration and bedding inclination. The removed volume shows an increasing trend along with the confining stress, and the maximum removed volume appears at $0^{\circ}$, which indicates that the strength of the bedding plane is weakened and more easily broken by the disc cutter under the same conditions. The specific energy decreases with increasing confining stress. Among all the tests, the specific energy of $\alpha=0^{\circ}$ and $90^{\circ}$ are smaller than those of the $\alpha$ values of other inclinations, and the specific energy achieves a maximum at $\alpha=60^{\circ}$ with a confining stress of $6 \mathrm{MPa}$, which means that this test displays the most efficient penetration.

\subsection{Effect of Bedding Inclination on Penetration Behaviour.} Figure 7 shows the variations in the peak force, removed volume, and specific energy with the bedding inclination. We can see that the peak force shows an increasing trend with bedding inclination in the first penetration, which indicates that a greater pressure is needed to reach the same penetration depth with the orientation of bedding plane and the disc cutter from parallel to vertical. At low confining stresses (4 MPa and $6 \mathrm{MPa}$ ), the bedding inclination has no obvious effect on the removed volume, because the failure pattern is the extension of cracks below the disc cutter. These cracks do not pass through entirely and form large slices. With increasing confining stress $(8 \mathrm{MPa}$ and $10 \mathrm{MPa})$, the influence of bedding inclination on specific energy gradually 

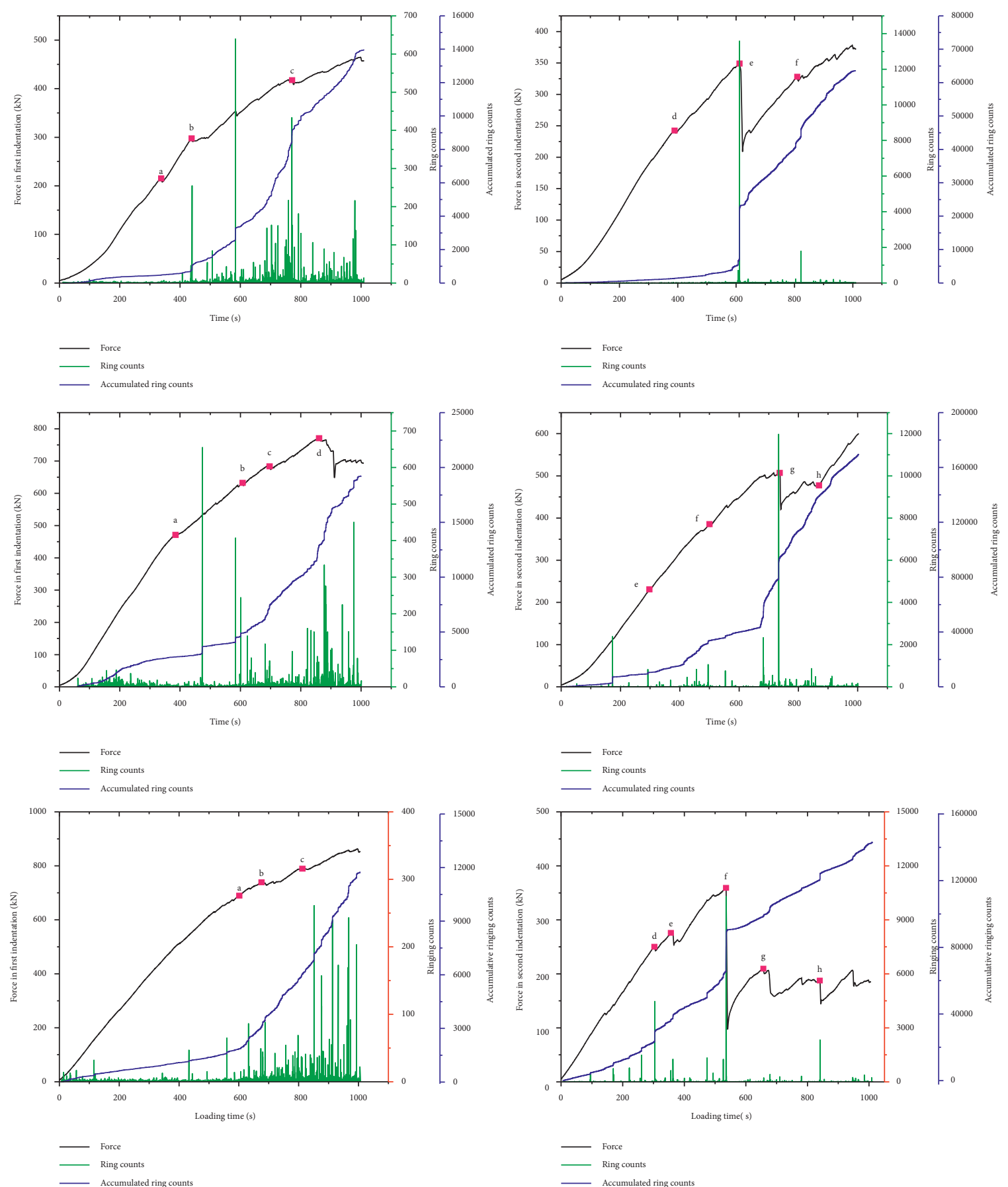

Figure 8: Acoustic emissions for the $\alpha=30^{\circ}, \alpha=60^{\circ}$, and $\alpha=90^{\circ}$ specimens under various confining stresses.

weakens, which indicates that the high confining stress restrains the anisotropy of the bedding plane, which approximates the energy needed to break unit volume rock at different inclinations.

3.4. Acoustic Emission and Surface Crack Evolution. An acoustic emission (AE) system was employed to record the $\mathrm{AE}$ counts during the tests. The variations in the $\mathrm{AE}$ ringing counts and accumulated ringing counts with penetration forces under different confining stresses and inclinations $\left(\alpha=30^{\circ}, 60^{\circ}\right.$, and $\left.90^{\circ}\right)$ are plotted in Figure 8. From Figure 8, we can see that the curve could be generally divided into three stages: compaction stage (the stage I) where curve is concave at the beginning of loading, constant stiffness stage (the stage II) where curve is straight, and crack propagation stage (the stage III). During the stage I and stage II, the ringing counts are rare and thus show relative tranquillity. With increasing penetration depth, the cracks initiate and constantly propagate, and several local drops in the loading forces appear on the curves. Meanwhile, the $\mathrm{AE}$ ringing counts and accumulated ringing counts abruptly increase to 


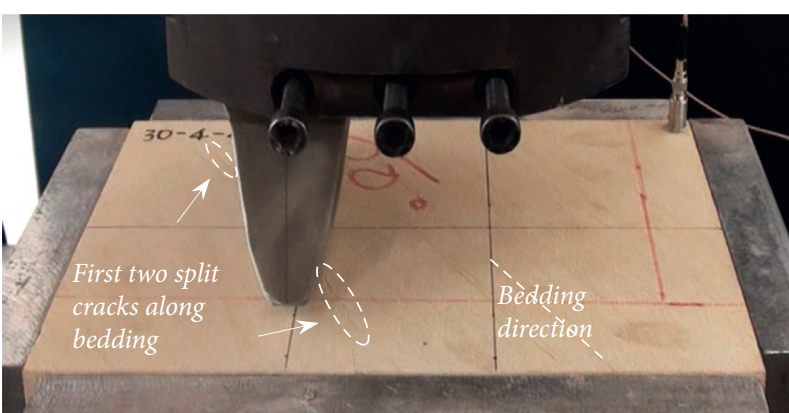

(a)

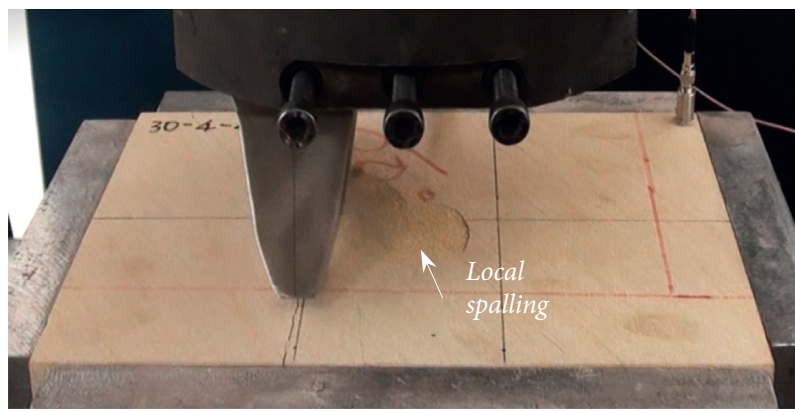

(c)

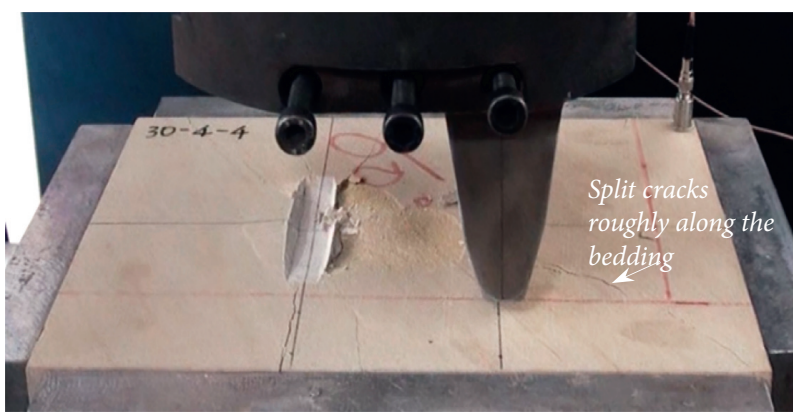

(e)

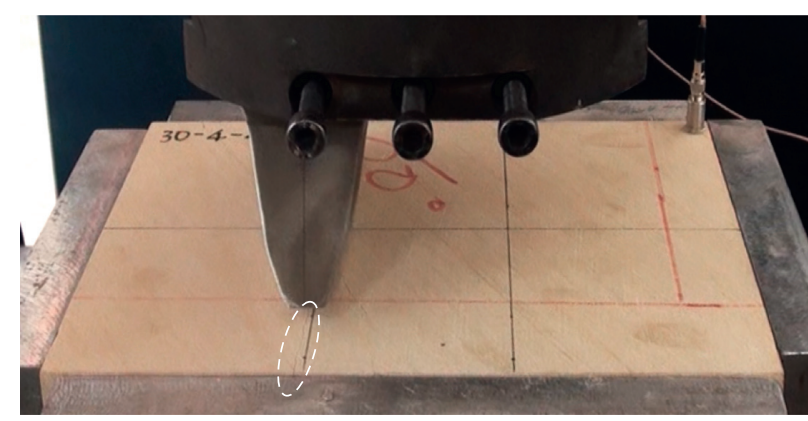

(b)

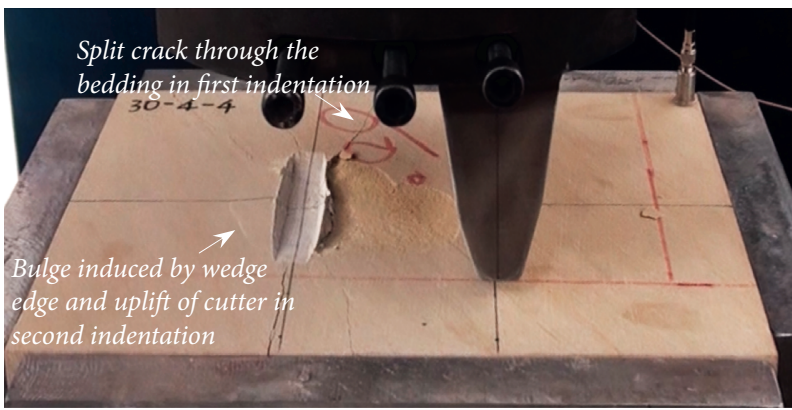

(d)

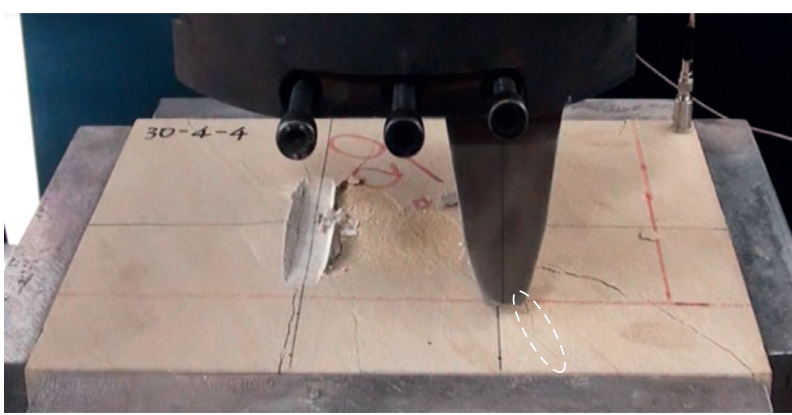

(f)

Figure 9: Surface crack evolution of the $\alpha=30^{\circ}$ specimen under $4 \mathrm{MPa}$ hydrostatic stress.

high numbers. At stage III, highly intensive and active ringing counts are monitored, and the accumulated ringing counts continue to rise.

During the second penetration, the $\mathrm{AE}$ ringing counts present a very low number at the beginning of loading. When the penetration force reaches the peak, we can see that the maximum $\mathrm{AE}$ ringing counts are obviously higher than the counts of the first penetration because the second penetration causes the specimen to break and form fragments between the two indentation nicks, and the failure is more acute. After the peak force, the AE ringing counts return still again, but the accumulated ringing counts continue to rise because the formed fragments continue breaking and moving by the disc cutter during penetration; therefore, a substantial quantity of ringing counts are monitored, and the accumulated ringing counts obviously increase. Moreover, the AE ringing counts and accumulated ringing counts generated by the second penetration are larger than the counts of the first penetration, which indicates that the acoustic signal is more active during the second penetration.

The evolution of surface cracks at bedding inclinations of $30^{\circ}, 60^{\circ}$, and $90^{\circ}$ is shown in Figures 9-11, respectively, corresponding to the image in Figure 8. For the specimen under a hydrostatic stress of $4 \mathrm{MPa}$ at a bedding inclination of $30^{\circ}$, as shown in Figure 9, the first split crack occurs along the bedding plane beside the disc cutter, and then a short crack parallel to the disc cutter appears at the end of the indentation nick. With increasing penetration depth, some rock fragments locally spall from the surface of the specimen. During the second penetration, the first split crack is still roughly along the bedding plane and opens gradually by penetration. At the same time, a few split cracks are generated at the end of the indentation nick, but none of them distinctly pass through and thus cause bulging between the two indentations. Thus, crack propagation is the main failure mode at low confining stress, and there is only local spalling on the surface rather than obvious breakage. Furthermore, 


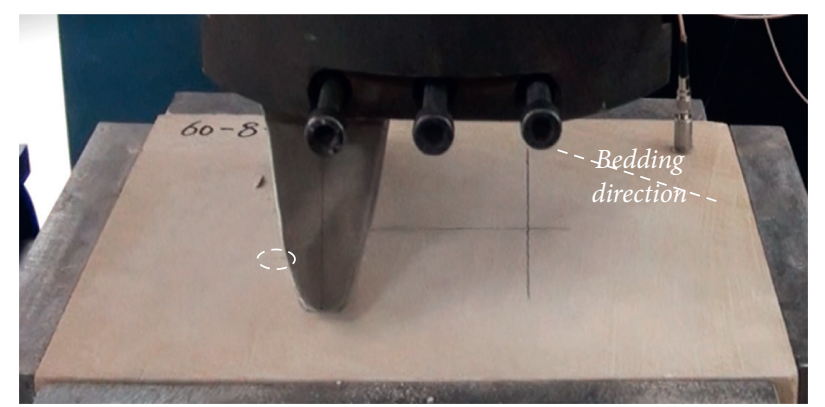

(a)

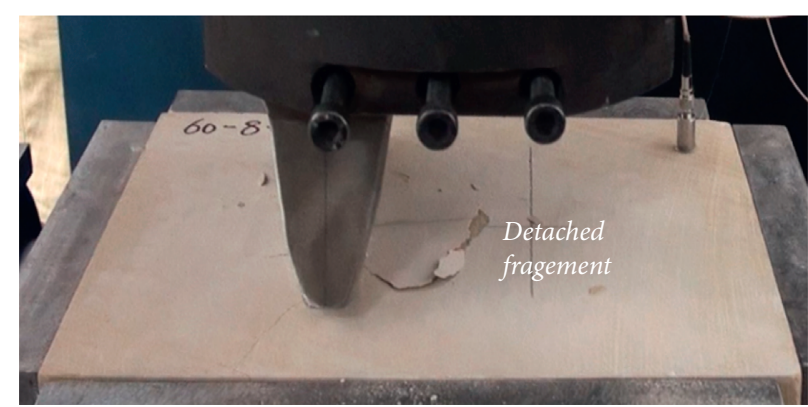

(c)

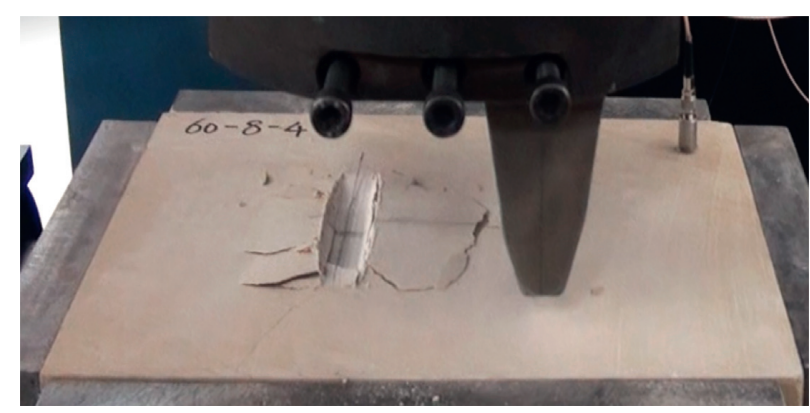

(e)

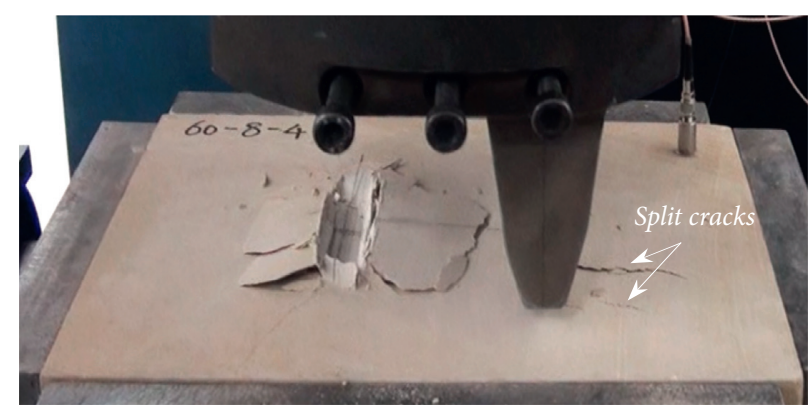

(g)

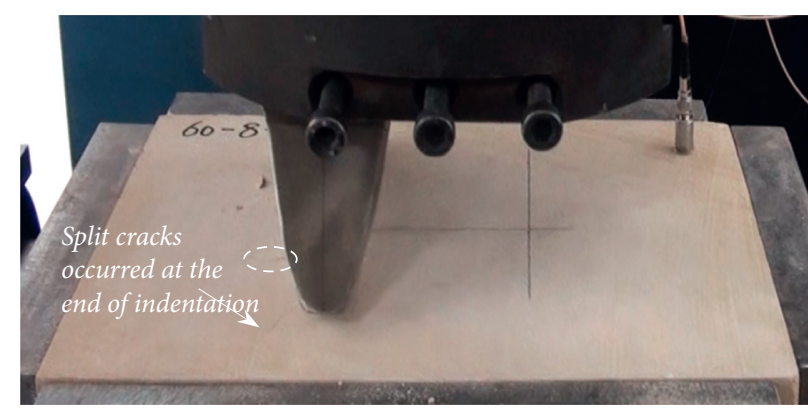

(b)

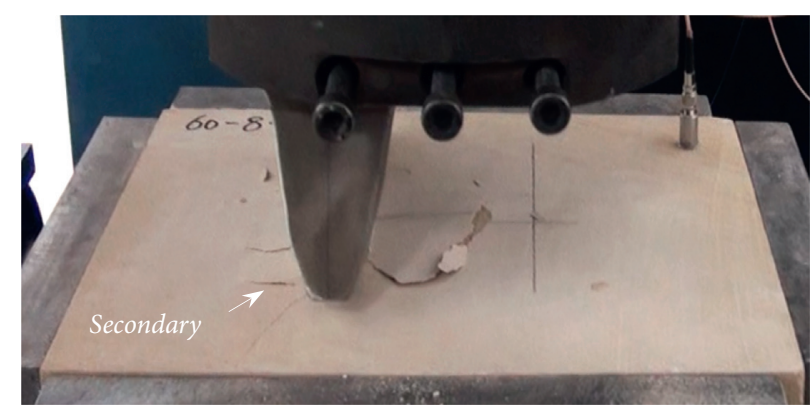

(d)

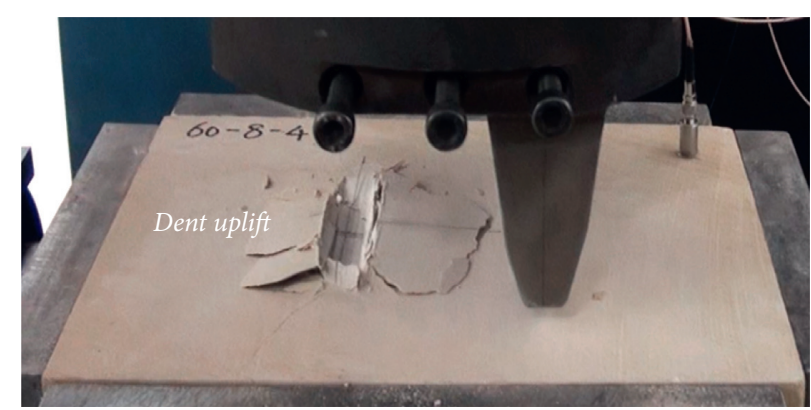

(f)

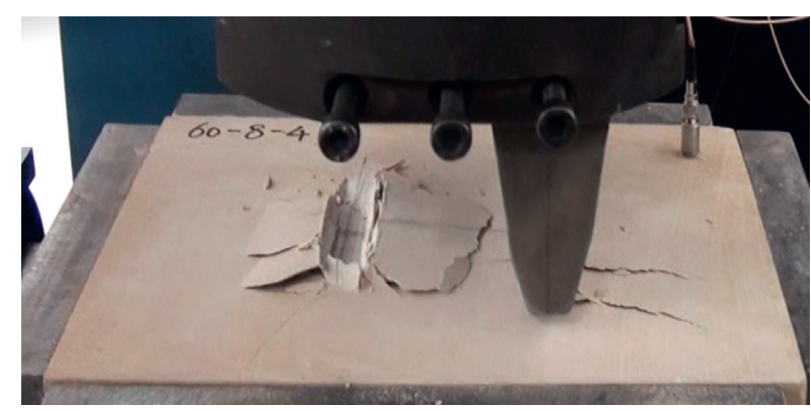

(h)

FIGURE 10: Surface crack evolution of the $\alpha=60^{\circ}$ specimen under a maximum principal stress of $8 \mathrm{MPa}$.

the peak forces of the two penetrations are close, which indicates that the peak force of the second penetration is relative to the extent of breakage from the first penetration.

As shown in Figure 10, some tiny pieces of rock fragments are spalled from the rock mass at the beginning of loading, and split cracks also occur beside the disc cutter at the end of the indentation nick. With increased loading, the initiation cracks propagate and extend. Then, a crack occurs at the end of the indentation nick and across the bedding plane. Finally, fragments are spalled from the surface of the specimen to the right of the disc cutter. During the second penetration, the dent and fragments generated by the first penetration are gradually uplifted; subsequently, two cracks appear to the right of the disc cutter, and the direction is parallel to the principal stress. Similar to Figure 9, no distinct cracks pass through, bulges appear between the two indentations, and a broken zone is generated around the first indentation.

As shown in Figure 11, we can first see that local spalling occurs beside the disc cutter, and split cracks are generated at 


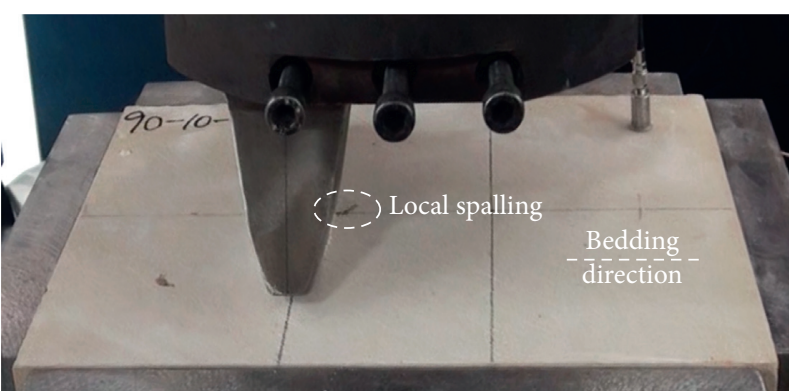

(a)

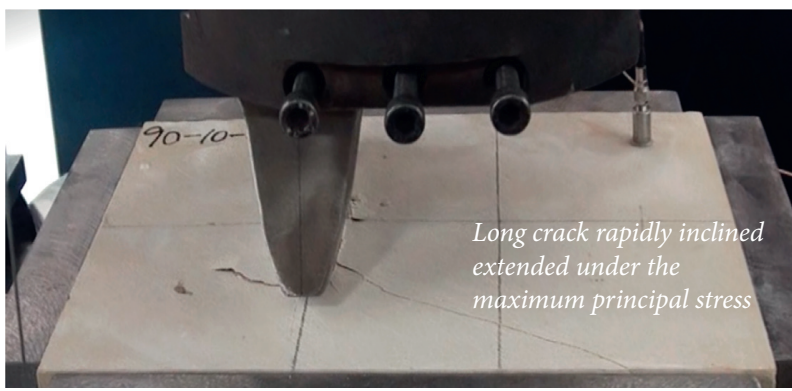

(c)

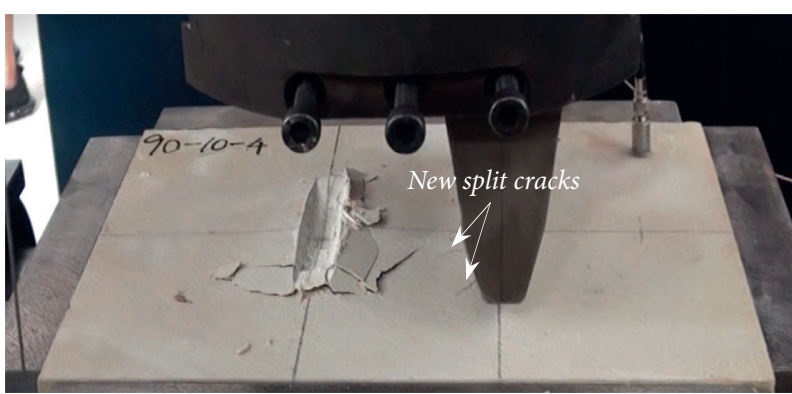

(e)

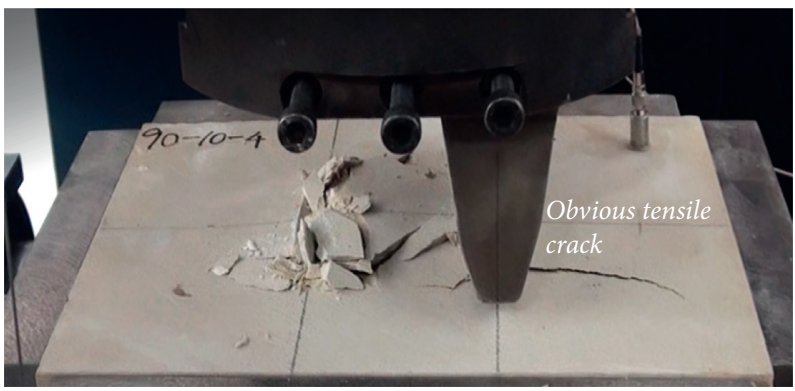

(g)

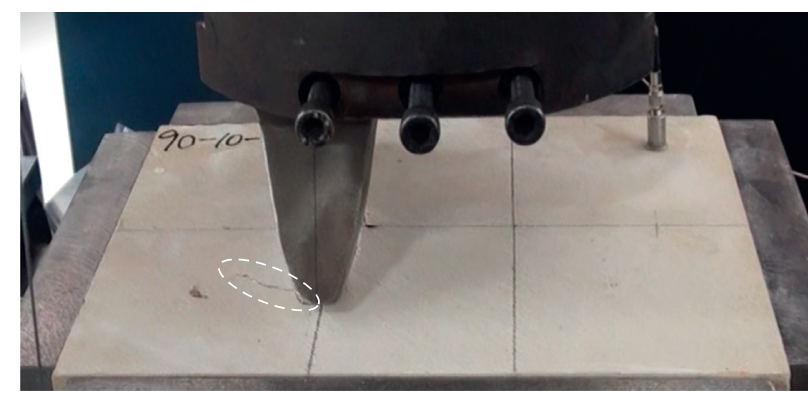

(b)

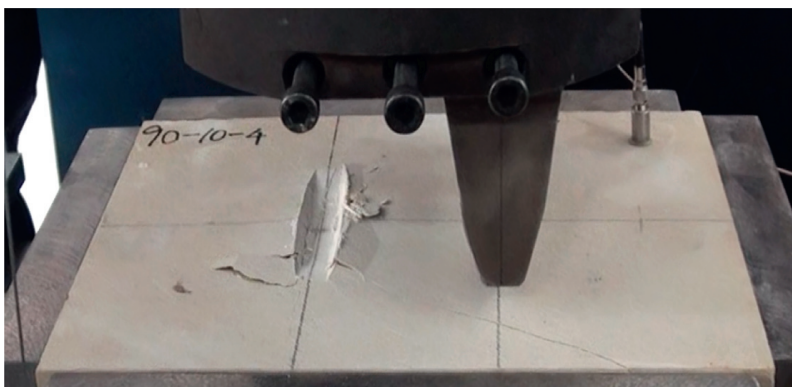

(d)

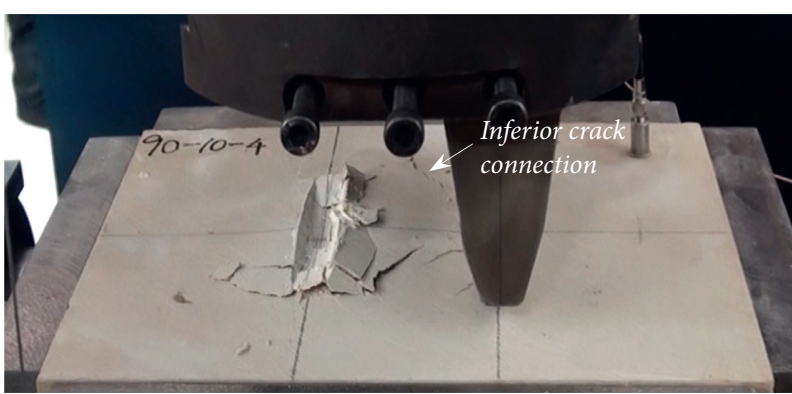

(f)

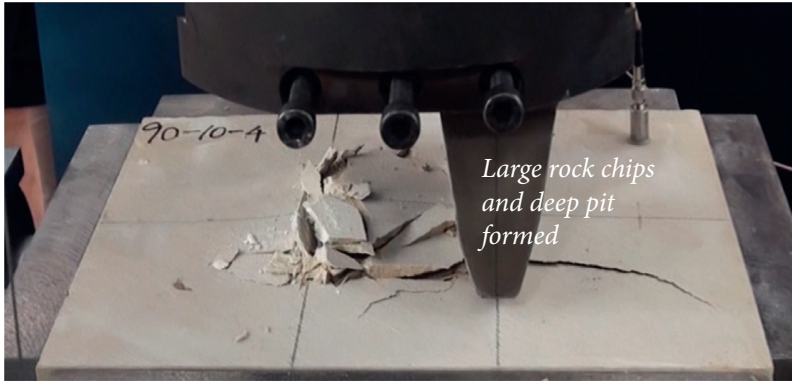

(h)

Figure 11: Surface crack evolution of the $\alpha=90^{\circ}$ specimen under a maximum principal stress of $10 \mathrm{MPa}$.

the end of the indentation nick; then, the long crack rapidly extends to the boundary of the specimen under the maximum principal stress. During the second penetration, new split cracks are generated around the disc cutter and extend to the broken zone by first penetration, finally forming large rock chips and deep pits. With increased loading, the broken fragments gradually uplift. Because the disc cutter has a wedge-shaped angle, the rock mass to the right of the disc cutter is also eventually lifted.

The final failure modes of the rock surface by two penetrations at bedding inclinations of $0^{\circ}, 45^{\circ}$, and $90^{\circ}$ are shown in Figure 12. It could be seen that the broken zone and depth rise with increasing confining stress. For the specimens under maximum stresses of $4 \mathrm{MPa}$ and $6 \mathrm{MPa}$ at a bedding inclination of $0^{\circ}$, the specimen fractures along the bedding plane, and there is no distinct bulge between the two indentations. Thus, the peak forces are closer after the two penetrations, and the first penetration has a small influence on the second penetration. When the maximum principal stress rises to $8 \mathrm{MPa}$ and $10 \mathrm{MPa}$, the cracks cross the bedding plane at the end of the indentation nick, and a distinct bulge is generated between the two indentation 


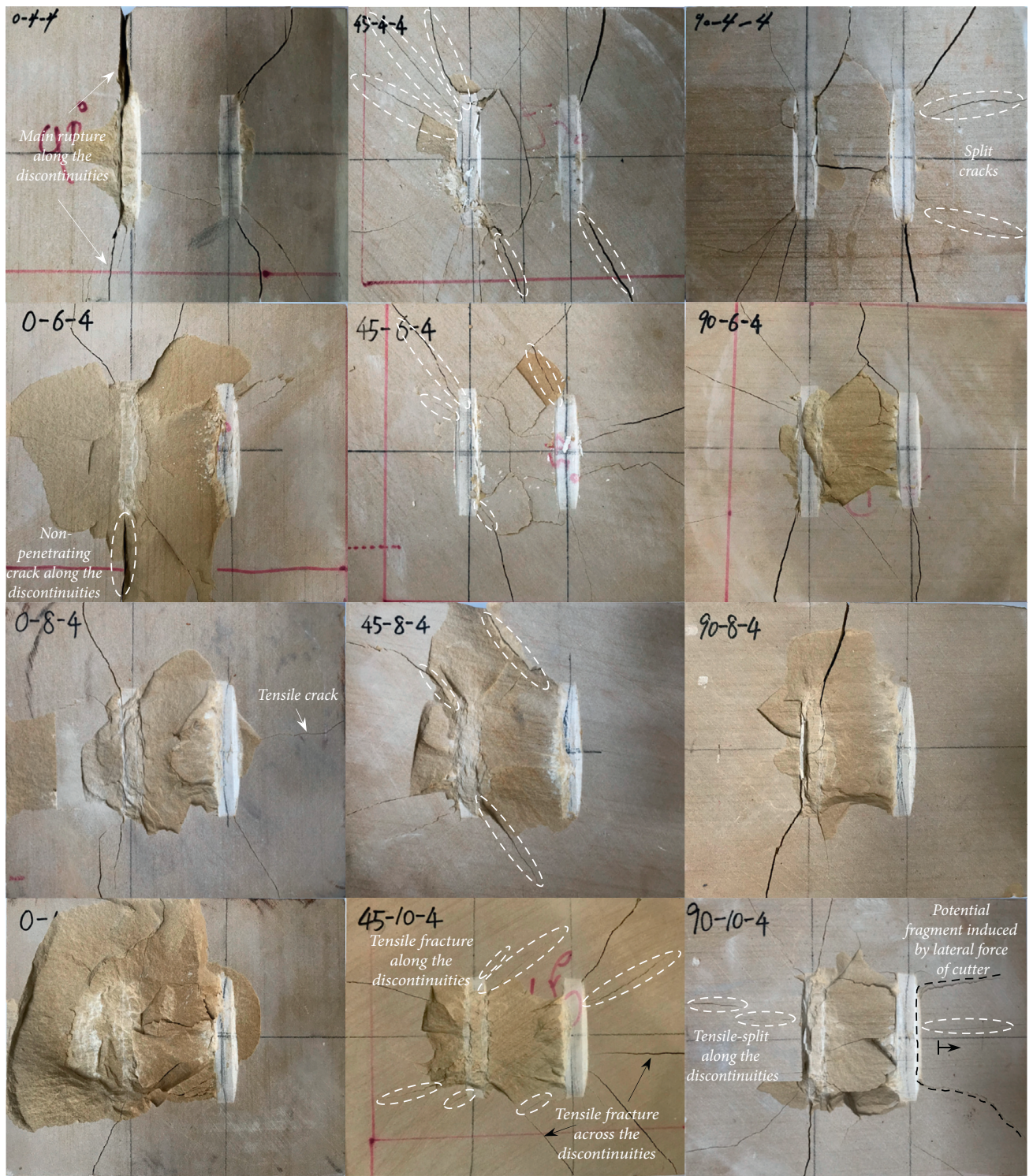

FIgURE 12: The ultimate failure mode of surface cracks for $\alpha=0^{\circ}, 45^{\circ}$, and $90^{\circ}$ samples.

nicks. Meanwhile, some tiny cracks occur parallel to the principal stress orientation and cross the bedding plane vertically. This reveals that with increasing confining stress, the leading role of failure by the bedding plane is weakened. At a bedding inclination of $45^{\circ}$, we can see that many cracks are generated on the surface, and these cracks mainly run along the bedding direction, which may be the main reason for the bearing capacity of $45^{\circ}$ being lower than the $30^{\circ}$ and $60^{\circ}$. With increasing inclination, the effect of bedding is decreased. At the bedding inclination of $90^{\circ}$, the fracture zone is smaller than that at the other inclinations, and the fracture pattern is hardly influenced by the bedding inclination.

3.5. Internal Crack Analysis. To investigate the internal cracks of the layered sandstone under penetration, X-ray computed tomography (CT) scanning was employed to scan the failure specimens after the penetration tests. The viewport of the CT scanning was selected as $153.6 \mathrm{~mm}$ $\times 153.6 \mathrm{~mm} \times 151.2 \mathrm{~mm}$. In each CT image, there were $512 \times 512$ pixels with $0.3 \mathrm{~mm} \times 0.3 \mathrm{~mm}$ resolution, and the coordinates used are shown in Figure 2.

Figures 13-15 show the CT images in the $X, Z$, and $Y$ planes for the $\alpha=0^{\circ}, 45^{\circ}$, and $90^{\circ}$ specimens under a maximum principal stress of $6 \mathrm{MPa}$ to illustrate the effect of the inclination angle on the distribution of internal cracks. In Figure 13, for each specimen, three sets of vertical crosssections with X-coordinates of $-35 \mathrm{~mm}, 0 \mathrm{~mm}$, and $35 \mathrm{~mm}$ are selected. At an inclination of $0^{\circ}$, a distinct crack is generated along the bedding direction under the indentation, and many fragments are spalled from the specimen and form a large area of failure around the two indentation nicks. However, the rock mass below the surface remains intact 

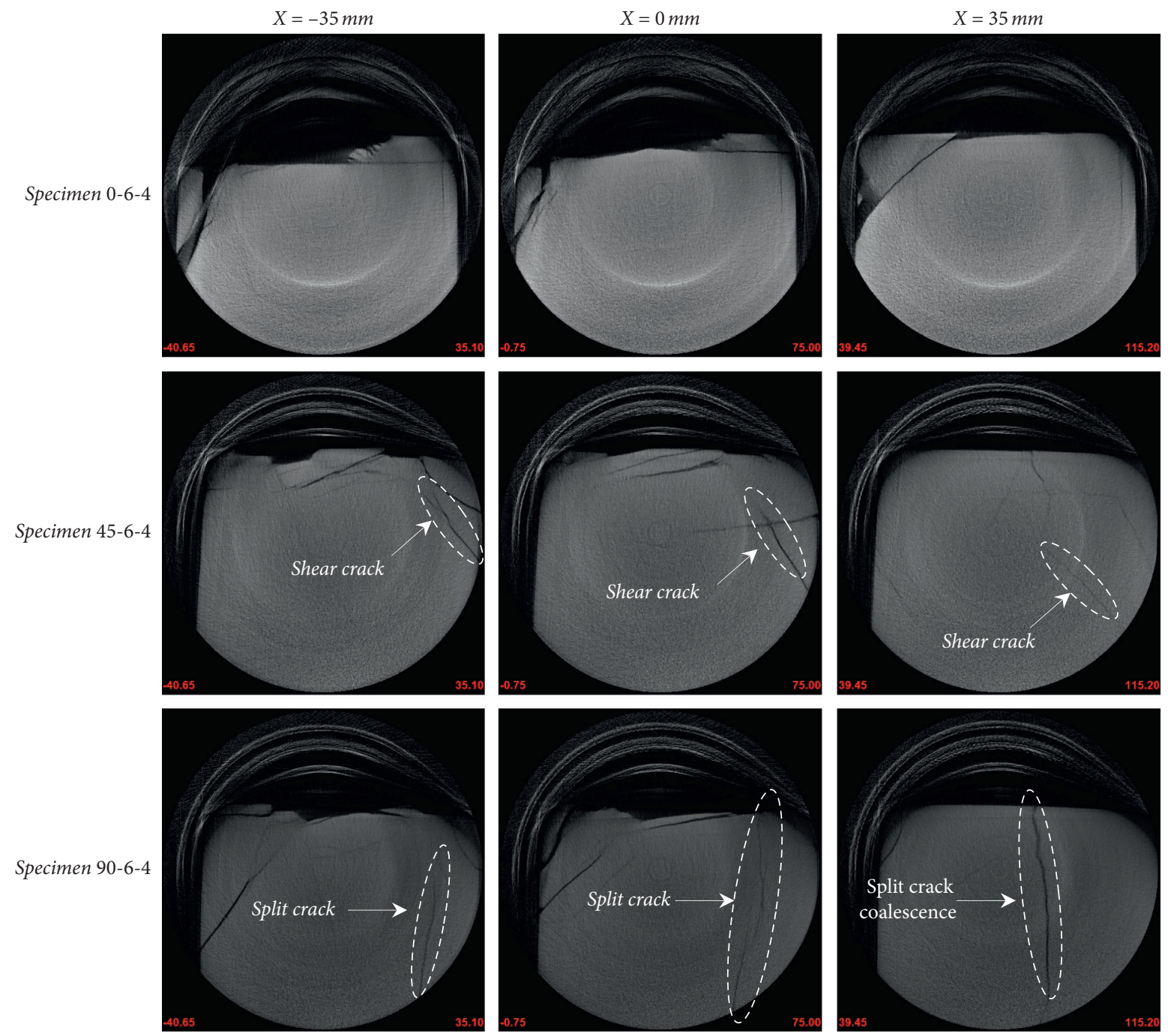

FIGURE 13: CT images in the X plane for the $\alpha=0^{\circ}, 45^{\circ}$, and $90^{\circ}$ specimens under a maximum principal stress of $6 \mathrm{MPa}$.

after failure, and no cracks occur, which indicates that the majority of indentation energy is consumed by violent failure on the surface and that the failure is controlled by the bedding plane. At an inclination of $45^{\circ}$, some fragments are spalled from the rock mass, and shear cracks occur at a certain depth under the indentation nick and extend to the free surface of the specimen, which indicates that with increasing bedding inclination, the influence of the bedding plane on failure gradually recedes. At an inclination of $90^{\circ}$, tensile cracks clearly occur under the indentation nick and extend vertically to the bottom of the specimen. However, the failure on the surface is not as severe as that at the other inclinations.

In Figure 14, for each specimen, three sets of horizontal cross-sections with Z-coordinates of $7 \mathrm{~mm}, 21 \mathrm{~mm}$, and $52 \mathrm{~mm}$ are selected. At an inclination of $0^{\circ}$, a large pit forms under the indentation from the surface to a certain depth, the fracture can still be clearly seen at $Z=21 \mathrm{~mm}$, and the direction runs along the bedding inclination. However, the rock mass is almost intact at $Z=52 \mathrm{~mm}$, and no distinct cracks can be observed, which indicates that the failure is mainly generated in the shallow part of the specimen. At an inclination of $45^{\circ}$, massive cracks are initiated on the surface of the specimen, and these cracks propagate and coalesce to form a crack network. As shown in Figure 14, the cracks are large and distinct at $Z=7 \mathrm{~mm}$ but decrease at $Z=21 \mathrm{~mm}$ and only a few at $Z=52 \mathrm{~mm}$. This indicates that a number of these cracks are surface cracks. With increasing bedding inclination, the cracks extend deeper, and the failure mode from the cracks running along the bedding plane reverts to cracks extending to depth. At an inclination of $90^{\circ}$, there are fewer cracks at $\alpha=45^{\circ}$ at $Z=7 \mathrm{~mm}$ and $21 \mathrm{~mm}$ but more distinct cracks at $Z=52 \mathrm{~mm}$, which indicates that the cracks extend vertically to a greater depth. 


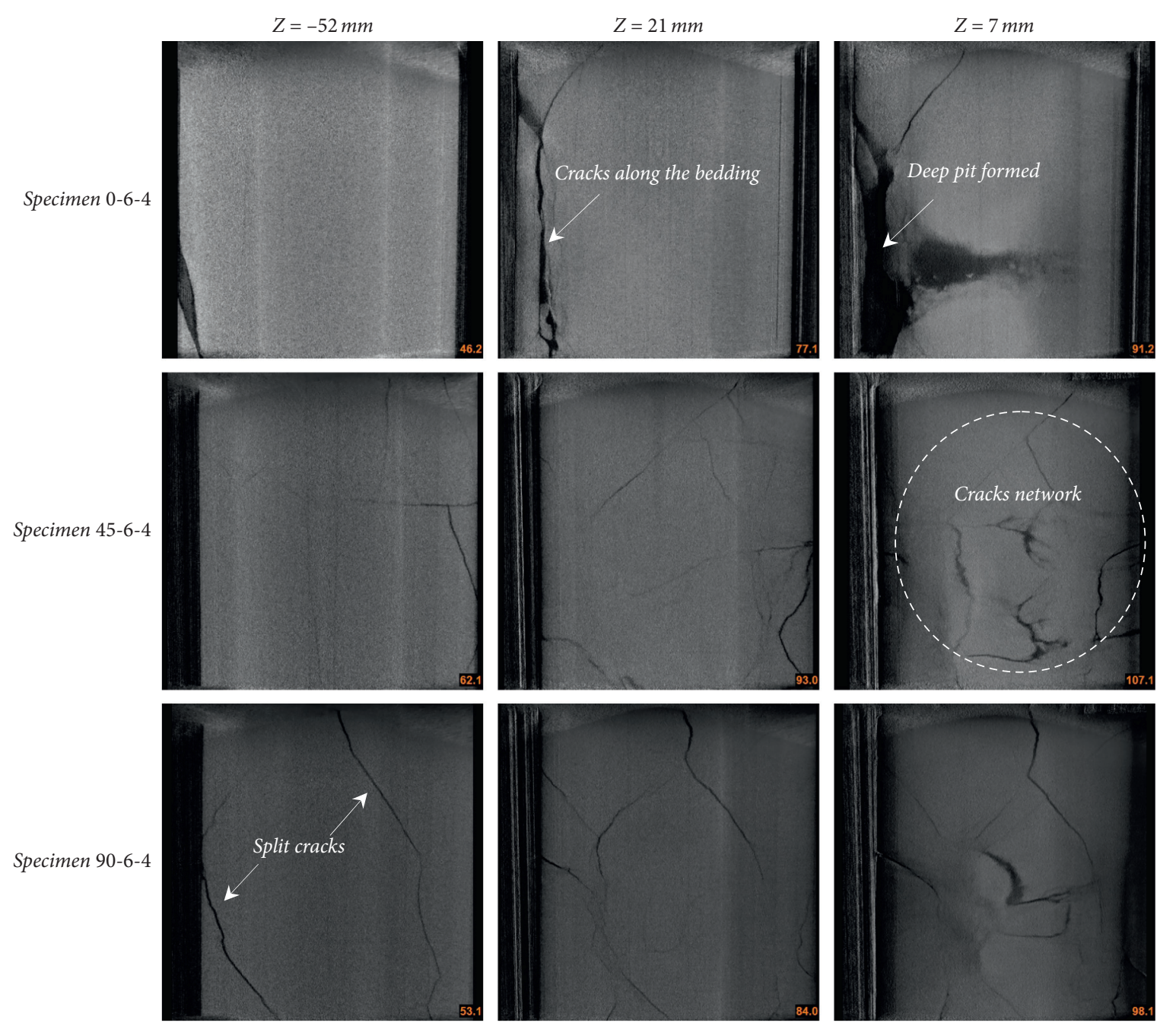

FIGURE 14: CT images in the $\mathrm{Z}$ plane for the $\alpha=0^{\circ}, 45^{\circ}$, and $90^{\circ}$ specimens under a maximum principal stress of $6 \mathrm{MPa}$.

In Figure 15, for each specimen, three sets of vertical cross-sections with $Y$-coordinates of $-35 \mathrm{~mm}, 0 \mathrm{~mm}$, and $35 \mathrm{~mm}$ are selected. At an inclination of $0^{\circ}$, it can be clearly seen that a deep crushed zone is formed by the first penetration at $Y=-35 \mathrm{~mm}$, and a distinct indentation forms with a shape similar to the disc cutter by the second penetration at $Y=35 \mathrm{~mm}$. The fragments are spalled from the rock mass between the two indentation nicks; thus, concavity can be observed at $Y=0 \mathrm{~mm}$. At an inclination of $45^{\circ}$, it sinks at $Y=-35 \mathrm{~mm}$ and $35 \mathrm{~mm}$ but bulges at
$Y=0 \mathrm{~mm}$ because the rock mass between the two indentation nicks is uplifted by the second penetration. The failure is slighter than $\alpha=0^{\circ}$ on the surface, but some cracks extend vertically to a certain depth. At an inclination of $90^{\circ}$, the median crack is initiated from the crushed zone and propagates vertically to the bottom of the specimen, side cracks appear from the crushed zone on both sides of the disc cutter and tend to deflect towards the rock-free surface, and the failure is hardly influenced by the bedding plane. 

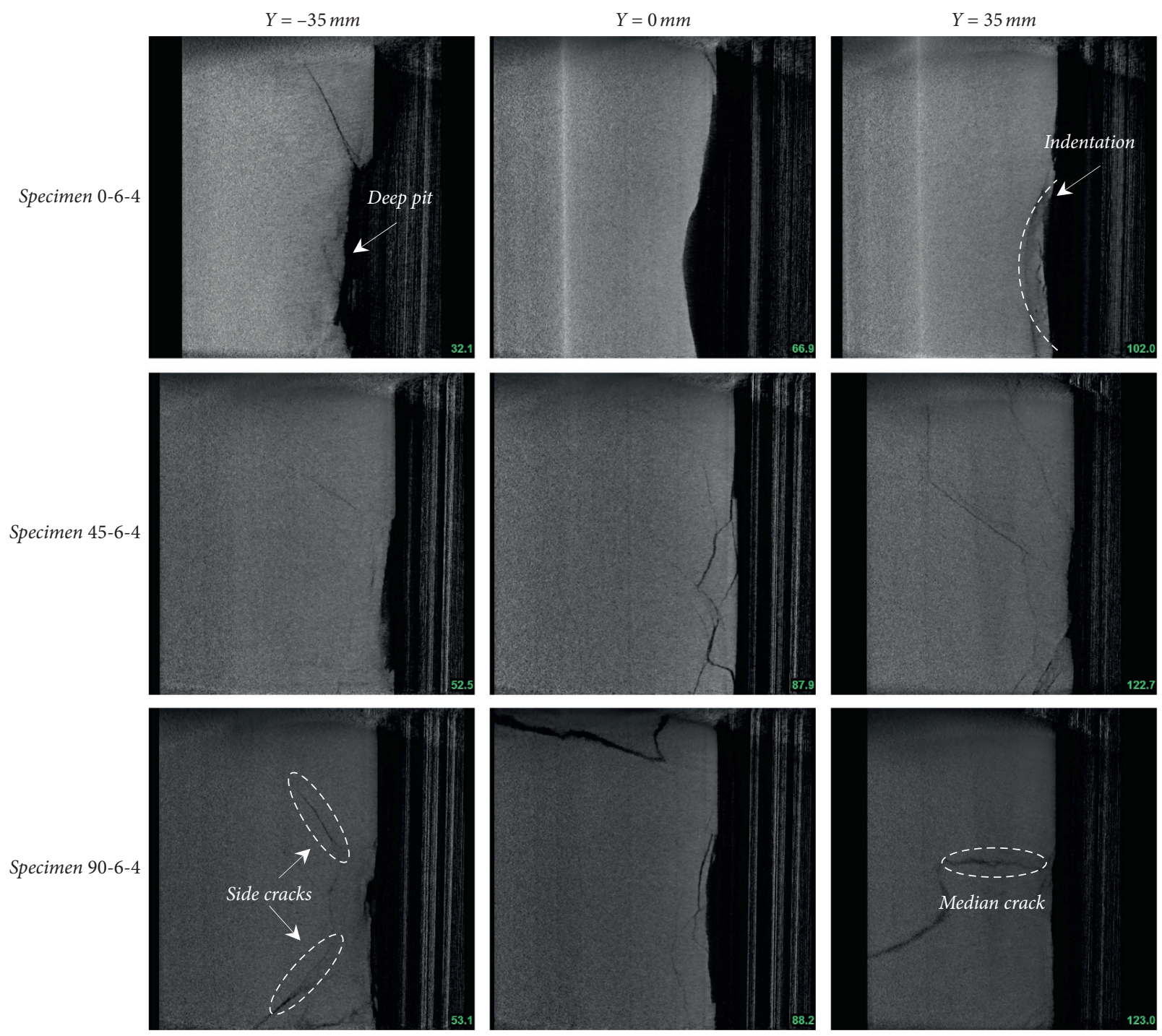

Figure 15: CT images in the Y plane for the $\alpha=0^{\circ}, 45^{\circ}$, and $90^{\circ}$ specimens under a maximum principal stress of $6 \mathrm{MPa}$.

\section{Conclusions}

In this paper, penetration tests by the disc cutter were conducted to investigate the failure mode of layered sandstone with a true triaxial compression system. A DV recorder and an acoustic emission (AE) system were used to record the failure process, and the X-ray micro-CT scanning method was employed to analyse the internal crack distribution. In terms of the results obtained, the breakage mechanism of layered sandstone under different confining stresses and bedding inclinations was further understood.

The confining stress had an important effect on the failure mode of the layered sandstone. Under low confining stress, the failure mode of the specimen was mainly characterized by the propagation of cracks. The cracks first occurred at the end of the indentation nick and then extended along the bedding plane. With increasing confining stress, the failure mode turned to be local crushing. The cracks passed through on the surface, and large rock chips spalled from the specimen and formed a deep pit between the two indentations.

The failure mode of layered sandstone was distinctly different from that of intact rock. When the bedding inclination was $0^{\circ}$, the bedding plane was parallel to the disc cutter. In this case, the cracks mainly occurred along the bedding plane, the majority penetration energy was consumed by the strong failure on the surface, and the failure focused on a shallower depth but a larger area around the disc cutter. With increasing inclination, the effect of the bedding plane gradually receded. Cracks along the principal stress direction also occurred on the surface, and various cracks extended and formed a crack network. Furthermore, the cracks propagated to a certain depth under the indentation nicks. When the inclination increased to $90^{\circ}$, the failure was hardly affected by the bedding plane, and the median crack initiated from the crushed zone and propagated vertically until reaching the bottom of the specimen. Side cracks appeared from the crushed zone on both sides of 
the disc cutter and tended to deflect towards the rock-free surface.

The failure of the specimen penetrated by disc cutter was sequentially enabled to simulate the actual excavation. For the first penetration, the evolution of cracks could be generally divided into three stages: there were no distinct fractures in stage I and stage II, and ringing counts were rare. At stage III, the cracks constantly propagated, and highly active ringing counts were monitored; then, the penetration force reached its peak. The peak force resulted in a linear variation with the confining stress and an increasing trend along the bedding inclination, indicating that the confining stress and bedding inclination have important effects on the cutting performance. For the second penetration, the failure mode was mainly related to the broken status created by the first penetration, the failure process was more acute, and the acoustic signal was more active.

\section{Data Availability}

The data used to support the findings of this study are available from the corresponding author upon request.

\section{Conflicts of Interest}

The authors declare that they have no conflicts of interest.

\section{Acknowledgments}

This work was financially supported by the Teacher Development Research Foundation of Chengdu University of Technology (grant no. 10912-2019KYQD07278).

\section{References}

[1] Q. Gong, L. Yin, H. Ma, and J. Zhao, "TBM tunnelling under adverse geological conditions: an overview," Tunnelling and Underground Space Technology, vol. 57, pp. 4-17, 2016.

[2] A. Delisio, J. Zhao, and H. H. Einstein, "Analysis and prediction of TBM performance in blocky rock conditions at the Lötschberg Base Tunnel," Tunnelling and Underground Space Technology, vol. 33, pp. 131-142, 2013.

[3] M. R. Maleki and R. N. Dehnavi, "Influence of discontinuities on the squeezing intensity in high in situ stresses (a tunnelling case study; actual evidences and TBM release techniques)," Rock Mechanics and Rock Engineering, vol. 51, pp. 2911-2933, 2018.

[4] B. Hu, M. Sharifzadeh, X. T. Feng, W. B. Guo, and R. Talebi, "Roles of key factors on large anisotropic deformations at deep underground excavations," International Journal of Mining Science and Technology, vol. 31, no. 2, 2021.

[5] K. Wu, Z. Shao, S. Qin, W. Wei, and Z. Chu, "A critical review on the performance of yielding supports in squeezing tunnels," Tunnelling and Underground Space Technology, vol. 114, 2021.

[6] L. Yin, C. Miao, G. He, F. Dai, and Q. Gong, "Study on the influence of joint spacing on rock fragmentation under TBM cutter by linear cutting test," Tunnelling and Underground Space Technology, vol. 57, pp. 137-144, 2016.

[7] H. Q. Yang, Z. Li, T. Q. Jie, and Z. Q. Zhang, "Effects of joints on the cutting behavior of disc cutter running on the jointed rock mass," Tunnelling and Underground Space Technology, vol. 81, pp. 112-120, 2018.

[8] H. Yang, J. Liu, and B. Liu, "Investigation on the cracking character of jointed rock mass beneath TBM disc cutter," Rock Mechanics and Rock Engineering, vol. 51, pp. 1263-1277, 2018.

[9] N. Afrasiabi, R. Rafiee, and M. Noroozi, "Investigating the effect of discontinuity geometrical parameters on the TBM performance in hard rock," Tunnelling and Underground Space Technology, vol. 84, pp. 326-333, 2019.

[10] Y. Zhao, H. Yang, Z. Chen, X. Chen, L. Huang, and S. Liu, "Effects of jointed rock mass and mixed ground conditions on the cutting efficiency and cutter wear of tunnel boring machine," Rock Mechanics and Rock Engineering, vol. 52, no. 5, pp. 1303-1313, 2019.

[11] J. Liu, P. Cao, and D. Han, "Sequential indentation tests to investigate the influence of confining stress on rock breakage by tunnel boring machine cutter in a biaxial state," Rock Mechanics and Rock Engineering, vol. 49, no. 4, pp. 1479-1495, 2016.

[12] M. H. Leite and F. Ferland, "Determination of unconfined compressive strength and Young's modulus of porous materials by indentation tests," Engineering Geology, vol. 59, no. 3-4, pp. 267-280, 2001.

[13] Q. Liu, Y. Pan, J. Liu, X. Kong, and K. Shi, "Comparison and discussion on fragmentation behavior of soft rock in multiindentation tests by a single TBM disc cutter," Tunnelling and Underground Space Technology, vol. 57, pp. 151-161, 2016.

[14] K. Wu, Z. Shao, and S. Qin, "An analytical design method for ductile support structures in squeezing tunnels," Archives of Civil and Mechanical Engineering, vol. 20, p. 91, 2020.

[15] K. Wu, Z. Shao, S. Qin, N. Zhao, and H. Hu, "Analytical-based assessment of effect of highly deformable elements on tunnel lining within viscoelastic rocks," International Journal of Applied Mechanics, vol. 12, no. 3, Article ID 2050030, 2020.

[16] Z. Chu, Z. Wu, Q. Liu, B. Liu, and J. Sun, “Analytical solution for lined circular tunnels in deep viscoelastic burgers rock considering the longitudinal discontinuous excavation and sequential installation of liners," Journal of Engineering Mechanics, vol. 147, no. 4, 2021.

[17] Q.-M. Gong, J. Zhao, and Y.-Y. Jiao, "Numerical modeling of the effects of joint orientation on rock fragmentation by TBM cutters," Tunnelling and Underground Space Technology, vol. 20, no. 2, pp. 183-191, 2005.

[18] Q. M. Gong, Y. Y. Jiao, and J. Zhao, "Numerical modelling of the effects of joint spacing on rock fragmentation by TBM cutters," Tunnelling and Underground Space Technology, vol. 21, no. 1, pp. 46-55, 2006.

[19] H. Bejari and J. Khademi Hamidi, "Simultaneous effects of joint spacing and orientation on TBM cutting efficiency in jointed rock masses," Rock Mechanics and Rock Engineering, vol. 46, no. 4, pp. 897-907, 2013.

[20] S. F. Zhai, X. P. Zhou, J. Bi, and N. Xiao, "The effects of joints on rock fragmentation by TBM cutters using General Particle Dynamics," Tunnelling and Underground Space Technology, vol. 57, pp. 162-172, 2016.

[21] X. Liu, M. Xu, and P. Qin, "Joints and confining stress influencing on rock fragmentation with double disc cutters in the mixed ground," Tunnelling and Underground Space Technology, vol. 83, pp. 461-474, 2019.

[22] X.-P. Zhang, P.-Q. Ji, Q.-S. Liu, Q. Liu, Q. Zhang, and Z.-H. Peng, "Physical and numerical studies of rock fragmentation subject to wedge cutter indentation in the mixed ground," Tunnelling and Underground Space Technology, vol. 71, pp. 354-365, 2018. 
[23] M. Eftekhari, A. Baghbanan, and R. Bagherpour, "The effect of fracture patterns on penetration rate of TBM in fractured rock mass using probabilistic numerical approach," Arabian Journal of Geosciences, vol. 7, no. 12, pp. 5321-5331, 2014.

[24] J. Liu, P. Cao, and K. Li, "A study on isotropic rock breaking with TBM cutters under different confining stresses," Geotechnical and Geological Engineering, vol. 33, no. 6, pp. 1379-1394, 2015.

[25] J. Liu, Y. Chen, W. Wan, J. Wang, and X. Fan, "The influence of bedding plane orientation on rock breakages in biaxial states," Theoretical and Applied Fracture Mechanics, vol. 95, pp. 186-193, 2018. 